\title{
Chronic Simvastatin Treatments Attenuate Ethanol Withdrawal Syndrome in Rats
}

\author{
M. M. S. Carrocini ${ }^{1}$, A. L. R. L. Caxambú ${ }^{1}$, N. S. Kelle ${ }^{1}$, D. D. Lima ${ }^{2}$, J. N. Cruz ${ }^{3}$, D. D. Dal Magro ${ }^{4}$, \\ J. G. P. Cruz ${ }^{4 *}$ \\ ${ }^{1}$ Department of Medicine, Regional University of Blumenau, Santa Catarina, Brazil \\ ${ }^{2}$ Department of Pharmacy, University of Joinville Region, Santa Catarina, Brazil \\ ${ }^{3}$ Department of Medicine, University of the Extreme South of Santa Catarina, Santa Catarina, Brazil \\ ${ }^{4}$ Department of Natural Sciences, Regional University of Blumenau, Santa Catarina, Brazil
}

\begin{abstract}
Rodent models of ethanol withdrawal-induced anxiety have been used to explore the neurobiology underlying withdrawal and to evaluate the utility of therapeutic agents aimed at reducing withdrawal severity. Of the many tests of anxiety-like behavior, the elevated plus maze and open field are the most commonly used. In general, ethanol withdrawal decreases most or all of the individual behaviors recorded in these tasks, indicating the occurrence of an anxiogenic-like effect of withdrawal in rodents. Effects of sub-chronic simvastatin treatments on ethanol withdrawal syndrome were investigated in rats. Ethanol $(7.2 \% \mathrm{v} / \mathrm{v})$ was given to adult male Wistar rats by a liquid diet for 30 days. Sub-chronic (once daily) simvastatin (1 or $10 \mathrm{mg} / \mathrm{kg}$ ) or saline were administered to rats by oral gavage. After 24 hours of ethanol withdrawal on the simvastatin treatment rats were observed in behavior tests. The increases the time open arms entries in the elevated plus-maze and grooming in the open-field through the exposure to sub-chronic treatment with simvastatin in rats submitted to ethanol intake, indicating beneficial effects on ethanol withdrawal syndrome. Our results suggest that sub-chronic simvastatin treatment attenuates ethanol withdrawal syndrome in ethanol-dependent rats and this drug may be useful for treatment of ethanol-type dependence.
\end{abstract}

Keywords Elevated plus-maze, Ethanol withdrawal, Open-field, Rats, Simvastatin

\section{Introduction}

Clinically, simvastatin have been widely used to reduce serum low density lipoprotein (LDL) cholesterol by inhibiting the rate-limiting enzyme, hydroxymethylglutarylcoenzyme reductase. In addition, evidence show that simvastatin reduce the risk of ischemic heart disease events and cerebrovascular stroke, and have potential applications in multiple sclerosis, traumatic brain injury, Alzheimer's disease, and anxiety[1,2-5]. Despite growing evidence for a role of simvastatin in central nervous system diseases, there is relatively little knowledge of their direct psychoneurological impacts on the central receptors and its association with the behavioral effects.

Several lines of evidence have demonstrated that chronic administration of simvastatin does not change the cholesterol level in brain tissue and plasma of rodents[4,6-8]. It is reasonable to hypothesize that the simvastatin effects in central nervous system are possibly via a central mechanism independent of hypocholesterolemic properties. Interestingly, in

* Corresponding author:

jgcruz@furb.br (J. G. P. Cruz)

Published online at http://journal.sapub.org/ajmms

Copyright (C) 2012 Scientific \& Academic Publishing. All Rights Reserved human being study simvastatin indeed lowered plasma cholesterol[9]. The contradicting findings may result from the different cholesterol metabolisms in human being and rodent. We speculated that it was poor cholesterol-lowering effect by statins in rodents[8], unaffected the genes directly involved in cholesterol synthesis[10].

The first evidence, indicating the effects of simvastatin treatment on N-methyl-D-aspartate (NMDA) receptor binding density in the brain reveals possible NMDA antagonist-like effect, which provides an exciting and potential paradigm to decreased anxiety[4]. This study showed that compared with the saline group, treatment of male SpragueDawley rats with simvastatin at a high dose (10 mg/kg/day) produced a significant longer travelled distance and higher average velocity in an open-field arena suggesting the hyperlocomotive activity; whilst increased time travelled in the open arms in elevated plus-maze was also observed, reflecting reduced anxiety-like behavior[4].

Several studies showed that ethanol is a potent and selective inhibitor of the NMDA receptors and prolonged ethanol exposition leads to a compensatory "up-regulation" of these receptors resulting in enhanced NMDA receptor-mediated functions after removal of ethanol. These alterations are supposed to contribute to the development of ethanol tolerance, dependence as well as the acute and delayed signs of 
ethanol withdrawal[11]. In particular, the up-regulation of different subunits of the NMDA receptor[12,13] may cause hyperexcitability of the central nervous system during withdrawal or negative emotions such as dysphoria, irritability, anxiety and depression[14,15]. In accordance with numerous data in the literature ethanol withdrawal induces an anxiogenic effect in the elevated plus-maze[16,17] and decrease in locomotion measured in the open-field[18]. Therefore, negative modulators of NMDA receptors may be useful agents for the pharmacotherapy of alcoholism, attenuate not only the physical symptoms but also some affective and motivational components of alcohol withdrawal.

Anxiety-like behaviors are integral features of withdrawal from chronic ethanol exposure. In the experiments in the current study, we tested the hypothesis that anxiety can be regulated independently of other withdrawal signs and thus may be responsive to selective pharmacological agents such as simvastatin. Thus, the current study was focused on revealing whether this drug is effective in attenuating ethanol withdrawal or not.

\section{Materials and Methods}

\subsection{Subjects}

A total of sixty male Wistar albino rats (Rattus norvegicus), genetically heterogeneous, 3 to 5 months of age, weighing 220 to $310 \mathrm{~g}$, were obtained from the animal house of the Regional University of Blumenau. After arrival in the sectorial animal house of the laboratory, these animals were housed in groups of five per opaque plastic cage $(50 \times 30 \times 15 \mathrm{~cm})$, with wood shaving bedding and wire mesh tops, under a standard light cycle (12-h light/dark phase; lights on at 07:00 h), in a temperature-controlled environment $\left(23 \pm 1^{\circ} \mathrm{C}\right)$, and the relative humidity was $55 \pm 10 \%$. During the light and dark phase, the rats were exposed to a light intensity of approximately 500 and 0,025 lux, respectively. These lux values were chosen because they were the closest values (in our laboratory) possible to natural daytime and nighttime light. During the whole experimental period, the animals received commercial chow for rodents (Nuvital, PR, Brazil) and filtered tap water ad libitum. The room was entered at irregular intervals an average of once every 2 or 3 days for the purposes of cleaning cages, placing food and water, and so on. Animals were acclimatized to the animal housing facilities for at least 1 week before starting the experiments. The experiments reported in this article were performed in compliance with the recommendations of Brazilian Society of Neuroscience and Behavior (SBNeC), which are based on the US National Institutes of Health Guide for Care and Use of Laboratory Animals.

\subsection{Experimental Protocols}

Ethanol was given to the rats for 30 days in their drinking water. The concentration of ethanol was gradually increased from 3,5 to $7,2 \%(v / v)$. Control rats had free access to wa- ter[19]. They were randomized with ten rats per group orally administered with either simvastatin (1 or $10 \mathrm{mg} / \mathrm{kg} /$ day by oral gavage, Merck) or saline (controls). Twenty-four hours after the last treatment rats were submitted to behavioral tests. The time for anxiety-like behavior was based on previous results with rats, where the maximum effect was recorded 24 hours after the last ethanol[20,21].

\subsection{Behavioral tests}

The animals were submitted individually to the elevated plus-maze and open-field tests. All behavioral procedures were conducted during the light phase (between 8:00 and 12:00 h), when rodents are less active, in a sound-isolated room. To minimize possible circadian influences on rat, experimental and control observations were alternated. The observer stayed in the same room, $1 \mathrm{~m}$ or so away from the elevated plus-maze and open-field[22,23].

\subsubsection{Elevated Plus-Maze Test}

The apparatus consisted of two open arms $(50 \times 10 \mathrm{~cm})$ and two enclosed arms (50 x $10 \times 40 \mathrm{~cm}$ ) arranged in such a way that the two arms of each type were opposite to each other, and a central platform $(10 \times 10 \mathrm{~cm})$. The maze's height was $50 \mathrm{~cm}$ and the tests were conducted under dim red light (44 lx). Animals were exposed for $5 \mathrm{~min}$ to the red light in their own home cages before the testing procedure. Next, they were placed individually on the central platform of the plus-maze facing an open arm. During a 5 min test period the following measurements were recorded by observer: the time spent on the open arms, the number of entries in the open arms, the time spent on the closed arms, the number of entries in the enclosed arms and risk assessment. Risk assessment is measures comprised for time spent in the headdipping (exploratory movement of head/shoulders over the side of the maze), and stretched attend postures (exploratory posture in which the body is stretched forward then retracted to the original position without any forward locomotion). Thus, the closed arms and center platform were designated as "protected" areas (i.e., offering relative security) and the "time protected" for head-dipping and stretched attend postures calculated as the time of these behaviors displayed in or from the protected area. The measures that reflect anxiety-like levels in this test are the percentage of entries into open arms versus closed arms and the percentage of time spent in the open arms versus closed arms. We also included ethologically derived measures related to the defensive pattern of risk assessment behavior, which has been proven very sensitive to changes in anxiety[22].

\subsubsection{Open-Field Test}

The open-field consisted of a black circular box $(60 \mathrm{~cm}$ in diameter and $50 \mathrm{~cm}$ high). Each rat was placed in the central area and allowed to freely explore for $5 \mathrm{~min}$. The tests were conducted under dim red light (44 lx). The following parameters were recorded: time the movement of the animal between parts spent in the central or peripheral zones of the 
apparatus are scored (ambulation); time for which the animal did not move at all (freezing); time rearing (rising on the hind paws) and time the animal performed self-cleaning (grooming). The total time spent ambulation and freezing was determined as a measure of activity. Exploration behavior in the open-field has also been used as a measure of defensive behavior, where increased line rearing responses are suggestive of a decrease in defensive behaviors[23].

\subsection{Statistical Analysis}

The data were reported as means \pm SEM and were analyzed statistically by analysis of variance (ANOVA) followed by the Newman-Keuls post hoc test. Differences were considered to be significant when $\mathrm{p}<0,05$.

\section{Results}

Analysis of variance revealed significant differences between groups on the time spent by rats in the open arms of the plus-maze $(F=3.183 ; p<0,05$; Figure $1 \mathrm{~A})$. The experimental group had free access to water and ethanol, orally administered with either $1 \mathrm{mg} / \mathrm{kg}$ of simvastatin, increased the time spent in the open arms on the day of experiment when compared to $0 \mathrm{mg} / \mathrm{kg}$ of simvastatin treatment $(p<0,05)$. There was no significant difference in groups in the frequency of open arm entries $(F=1.469 ; p=0,2165$; Figure $1 \mathrm{~B})$, time spent in enclosed arm $(\mathrm{F}=1.509$; $\mathrm{p}=$ 0,2071; Figure 1C), and frequency of enclosed arm entries ( $F$ $=1.147 ; \mathrm{p}=0,3511 ;$ Figure 1D). In case of risk assessment time, there were significant differences between groups $(F=24.859 ; p<0,01$; Figure $1 E)$. The experimental group had free access to water and orally administered with 1 $\mathrm{mg} / \mathrm{kg}$ simvastatin increased the risk assessment time $(p<0,001)$. On the other hand, rats with ethanol withdrawal decreased this risk assessment time $(p<0,001)$, when compared to group had free access to water and $0 \mathrm{mg} / \mathrm{kg}$ of simvastatin treatment.

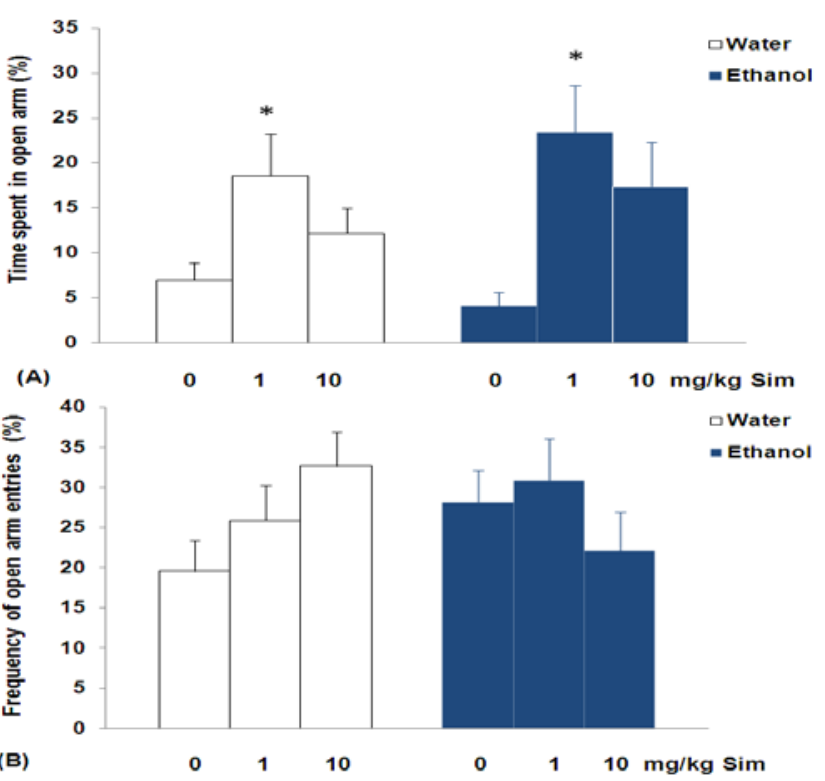

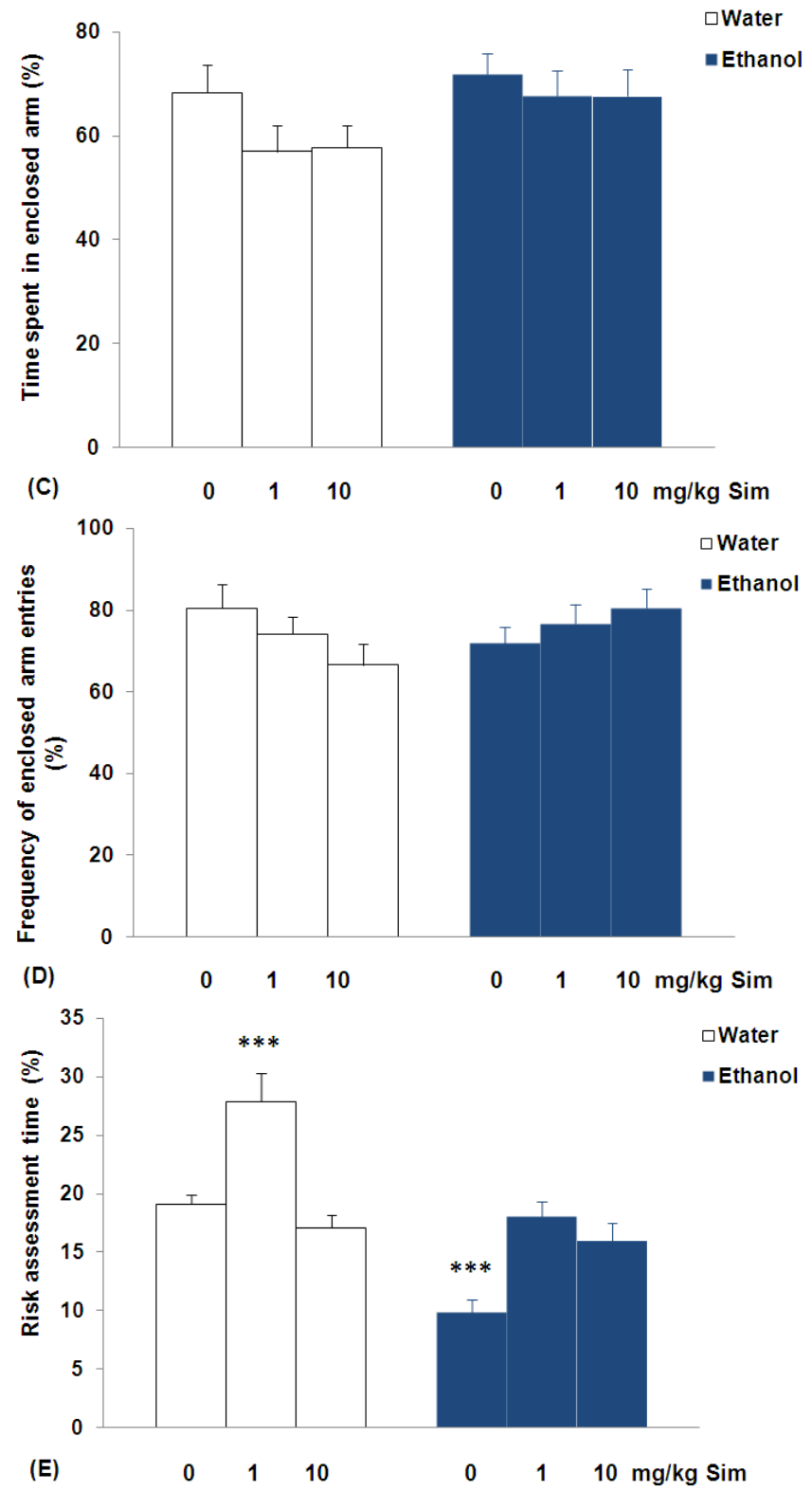

Figure 1. Behavioral responses in the elevated plus-maze of sub-chronic simvastatin treatment on ethanol withdrawal syndrome in rats: (A) \% time spent in open arm, (B) \% frequency of open arm entries, (C) \% time spent in enclosed arm, (D) \% frequency of enclosed arm entries, and (E) \% risk assessment time. Bars represent the means for each group and the vertical lines represent the standard errors of the means. Newman-Keuls test showed that groups with asterisks are significantly different versus the experimental group had free access to water and $0 \mathrm{mg} / \mathrm{kg}$ of simvastatin treatment $(\mathrm{n}=10$; ${ }^{*} \mathrm{p}<0,05$ and $\left.{ }^{* * *} \mathrm{p}<0,001\right)$.

Analysis of variance revealed significant differences between groups on the ambulation/interior zone time of the open-field $(\mathrm{F}=2.589 ; \mathrm{p}<0,05$; Figure $2 \mathrm{~A})$ and ambulation/outside zone time $(\mathrm{F}=2.781 ; \mathrm{p}<0,05$; Figure $2 \mathrm{~B})$. The experimental group ethanol withdrawal syndrome orally administered with either $0 \mathrm{mg} / \mathrm{kg}$ of simvastatin decreased ambulation/interior zone time and increased ambulation/outside zone time $(\mathrm{p}<0,05)$, compared with the other groups. In addition, increased time spent immobility $(\mathrm{F}=$ 3.820; $\mathrm{p}<0,05$; Figure 2C). Analysis of variance revealed significant differences between groups on the time spent 
rearing $(\mathrm{F}=3.712 ; \mathrm{p}<0,01$; Figure $2 \mathrm{D})$. The experimental group had free access to water and orally administered with either 1 or $10 \mathrm{mg} / \mathrm{kg}$ of simvastatin increased the time spent rearing $(p<0,05)$. Considering the time spent in the grooming, significant increase were found between ethanol withdrawal syndrome orally administered with either $1 \mathrm{mg} / \mathrm{kg}$ of simvastatin, compared with the other groups $(F=4.718$; $p<0,01$; Figure 2E).
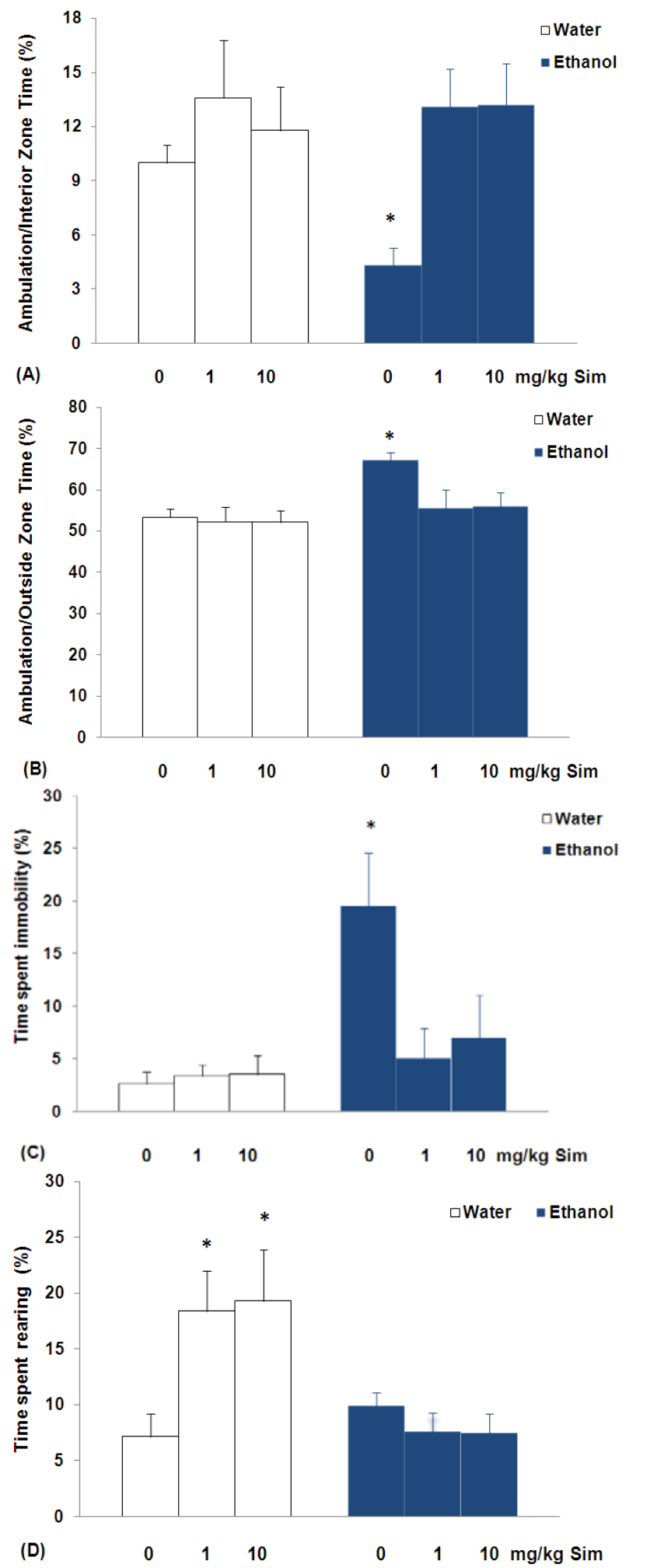

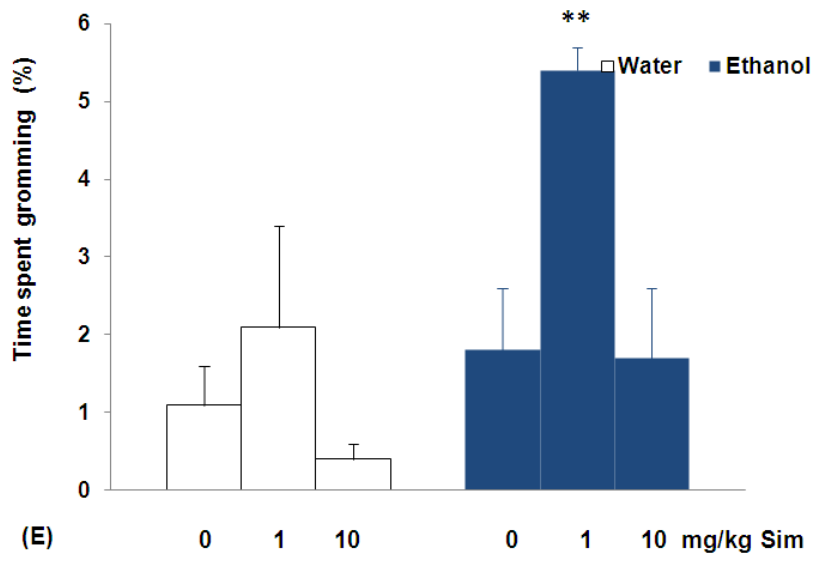

Figure 2. Behavioral responses in the open-field of sub-chronic simvastatin treatment on ethanol withdrawal syndrome in rats: (A) \% ambulation/interior zone time, (B) \% ambulation/outside zone time; (C) \% time spent immobility, (D) \% time spent rearing, and (E) \% time spent grooming. Bars represent the means for each group and the vertical lines represent the standard errors of the means. Newman-Keuls test showed that groups with asterisks are significantly different versus the experimental group had free access to water and $0 \mathrm{mg} / \mathrm{kg}$ of simvastatin treatment $\left(\mathrm{n}=10\right.$; ${ }^{*} \mathrm{p}<0,05$ and $* * \mathrm{p}<0,01)$.

\section{Discussion}

The results of experiment suggest that exposure to sub-chronic treatment with simvastatin reduced anxiety levels in rats submitted to ethanol or water intake. These symptoms were observed as an increase in time open arms entries of the elevated plus-maze (Figure 1A). The elevated plus-maze is a widely used animal model of anxiety that is based on two conflicting tendencies; the rodent's drive to explore a novel environment and it's aversion to open spaces. Thus anxious animals will spend most time in the closed arms while less anxious animals will explore open areas longer[22]. In addition, rats submitted to water intake increased the time spent in the risk assessment when treated with simvastatin (Figure 1E). These ethological elements, which include stretched attend postures (SAP) and head-dipping, have been linked through factor analysis to risk assessment, directed exploration, and displacement activity, respectively[24]. Furthermore, pharmacological studies have shown that the incorporation of such measures in plus-maze scoring not only reduces the likelihood of false positives and negatives[25], but also enhances the sensitivity of the model to novel anxiolytic[26]. However, rats submitted to ethanol intake decreased the time spent in the risk assessment (Figure 1E). Decreased risk assessment behavior was observed in rats after ethanol withdrawal, reinforcing the suggestion of an anxiogenic effect of ethanol. On the other hand, the analysis failed to show any anxiogenic profile for all doses of ethanol tested in rats. These effects were observed in the absence of significant changes in general locomotor activity, represented by enclosed arm entries (Figure 1D). These results strongly indicate that simvastatin treatment results in an improved coping with aversive situations, thus, leading to a reduced anxiety level in rats sub- 
mitted to ethanol or water intake. The evidence indicating the effects of simvastatin treatment on NMDA receptor binding density in the brain reveals possible NMDA antagonist-like effect, which provides an exciting and potential paradigm to decreased anxiety[4].

The differences in anxiotypic behavior expressed by these animals are not limited to their performance on the elevated plus-maze. The novel environment is an established measure of general anxiotypic behavior, and levels of locomotion and rearing in this paradigm can be used as indices of an anxiety-like state in rats[23]. The experimental group ethanol withdrawal syndrome orally administered with either 0 $\mathrm{mg} / \mathrm{kg}$ of simvastatin decreased ambulation/interior zone time and increased ambulation/outside zone time, with increased time spent immobility (Figures 2A, 2B and 2C) in the open-field. Locomotion can be assessed by time spent in each of two zones (central and peripheral) can be used in addition to the classical test as indicators of anxiety[27]. Traveling close to the wall is an important feature of the rats, and it has been suggested that the wall confers security while the center is anxiogenic[28]. So, the decrease the time spent in the ambulation/interior zone indicating anxiogenic effect in the experimental group ethanol withdrawal syndrome orally administered with either $0 \mathrm{mg} / \mathrm{kg}$ of simvastatin. In addition, increased immobility in the open-field is characteristic of increased levels of anxiety[29]. Consistent with our previous findings[19], the present data demonstrated that daily ethanol consumption over $7,2 \% \mathrm{v} / \mathrm{v}$ for 30 consecutive days produced physical dependence in rats.

It is also worth mentioning that ethanol interacts with receptors of the NMDA type for the excitatory amino acid transmitter glutamate[30], which has been shown to be involved in the mediation of anxiety-like behavior[31]. The ethanol is a potent and selective inhibitor of the NMDA receptors and prolonged ethanol exposition leads to a compensatory "up-regulation" of these receptors. The up- regulation of different subunits of the NMDA receptor[12,13] may cause anxiety during ethanol withdrawal[14,15]. Models of ethanol withdrawal in adult rodents have consistently demonstrated increases in anxiety during the withdrawal period after chronic exposure to ethanol[32].

Another behavior considered to be of an exploratory nature is rearing in the open-field[24]. Sub-chronically, simvastatin ( 1 or $10 \mathrm{mg} / \mathrm{kg} /$ day) increases the rearing in rats submitted to water intake. Thus the increase of spontaneous rearing in the present study can be attributed to the decreased anxiety-related behavior. Two recent studies using rats have demonstrated anxiolytic properties of simvastatin[4,33]. Both studies utilised Sprague-Dawley rats which were dosed with a tenfold greater statin dose and tested using anxiety specific behavioral paradigms (elevated plus-maze and/or open-field test). Interestingly, simvastatin $(1 \mathrm{mg} / \mathrm{kg} / \mathrm{day})$ increases the grooming in rats submitted to ethanol intake (Figure 2E). Low-stress comfort grooming is a spontaneous body care ritual which occurs as a transition from rest to activity[29]. The increases the time open arms entries and grooming through the exposure to sub-chronic treatment with simvastatin in rats submitted to ethanol intake, has some beneficial effects on ethanol withdrawal syndrome.

The ethanol is a potent and selective inhibitor of the NMDA receptors and prolonged ethanol exposition leads to a compensatory "up-regulation" of these receptors resulting in enhanced NMDA receptor-mediated functions after removal of ethanol[12,13]. The elucidation of the receptors mediating the anti-withdrawal effects of simvastatin in the present study a waits the testing of specific NMDA receptor in the rat brain. The evidence indicating the effects of simvastatin treatment on NMDA receptor binding density in the brain reveals possible NMDA antagonist-like effect, which provides an exciting and potential paradigm to decreased anxiety[4].

Chronic alcohol exposure produces neuroadaptive changes in glutamatergic synaptic transmission. Specifically, chronic alcohol produces up-regulation of NMDA receptor function and NMDA receptor-mediated glutamatergic synaptic transmission[34]. Microdialysis experiments indicate that chronic alcohol exposure produces increases in extracellular glutamate levels in brain, especially after single or repeated withdrawals[35]. These increases may be due to chronic alcohol-induced decreases in glutamate uptake[36], or perhaps changes in cystine/glutamate exchange[37].

Although attenuating the severity of ethanol withdrawal syndrome is very important, current treatment choices are very limited except for the use of benzodiazepines, it is generally understood that significant tolerance and dependence may result from their use. Therefore, negative modulators of NMDA receptors may be useful agents for the pharmacotherapy of alcoholism, attenuate not only the physical symptoms but also some affective and motivational components of alcohol withdrawal. In addition, acamprosate, a pharmacotherapeutic approved for treatment of alcoholic patients, modulates glutamatergic transmission via actions at NMDA receptors and/or metabotropic glutamate receptors [38]. Acamprosate dampens increased glutamate levels in abstinent alcoholics as measured by magnetic resonance spectroscopy[39] and reduces excessive alcohol drinking in those individuals, presumably by reducing craving and negative affect[40].

New developments at the forefront of preclinical research have begun to identify the therapeutic potential of molecular entities integral to the biological response to adversity, particularly molecules and processes that may pre-determine vulnerability or resilience, and those that may act to switch off or "unlearn" a response to an aversive event. The glutamate system is an interesting target in this respect, especially given the anxiety disorders. NMDA glutamate receptors are known to have a role in alcohol dependence and withdrawal[30]. Thus, NMDA receptor antagonists may be used to block the ethanol withdrawal syndrome. The present data demonstrated that simvastatin, with possible NMDA antagonist-like effect, attenuates the ethanol withdrawal in rats, suggesting that it can be a useful drug in the treatment of ethanol withdrawal. 


\section{Conclusions}

Our results suggest that simvastatin at high doses has some beneficial effects on ethanol withdrawal syndrome in rats. Because anxiety may be a complicating factor in alcohol withdrawal, future studies of this type are needed to provide focus for the effort to define selective and novel anti-anxiety agents for these disorders.

\section{REFERENCES}

[1] Sett AK, Robinson TG, and Mistri AK. Current status of statin therapy for stroke prevention. Expert Rev Cardiovasc Ther 9 (2011) 1305-14.

[2] Swindle JP, Potash J, Kulakodlu M, Kuznik A, and Buikema A. Drug utilization patterns and cardiovascular outcomes in elderly patients newly initiated on atorvastatin or simvastatin. Am J Geriatr Pharmacother 9 (2011) 471-82.

[3] Tramontina AC, Wartchow KM, Rodrigues L, Biasibetti R, Quincozes-Santos A, Bobermin L, Tramontina F, and Gonçalves CA. The neuroprotective effect of two statins: simvastatin and pravastatin on a streptozotocin-induced model of Alzheimer's disease in rats. J Neural Transm 118 (2011) 1641-9.

[4] Wang Q, Zengin A, Deng C, Li Y, Newell MKA, Yang GY, Lu Y, Wilder-Smith EP, Zhao H, and Huang XF. High dose of simvastatin induces hyperlocomotive and anxiolytic-like activities: The association with the up-regulation of NMDA receptor binding in the rat brain. Exp Neurol 216 (2009) 132-8.

[5] Zhang X, Tao Y, Troiani L, and Markovic-Plese S. Simvastatin inhibits IFN regulatory factor 4 expression and Th17 cell differentiation in CD4+ T cells derived from patients with multiple sclerosis. J Immunol 87 (2011) 3431-7.

[6] Mok SW, Thelen KM, Riemer C, Bamme T, Gultner S, Lutjohann D, and Baier M. Simvastatin prolongs survival times in prion infections of the central nervous system. Biochem Biophys Res Commun 348 (2006) 697-702.

[7] Selley ML. Simvastatin prevents 1-methyl-4-phenyl-1,2,3,6tetrahydropyridine induced striatal dopamine depletion and protein tyrosine nitration in mice. Brain Res 1037 (2005) 1-6.

[8] Schoonjans K, Peinado-Onsurbe J, Fruchart JC, Tailleux A, Fiévet C, and Auwerx J. 3-Hydroxy-3-methylglutaryl CoA reductase inhibitors reduce serum triglyceride levels through modulation of apolipoprotein C-III and lipoprotein lipase. FEBS 452 (1999) 160-4.

[9] Vega GL, Weiner MF, Lipton AM, Von Bergmann K, Lutjohann D, Moore C, and Svetlik D. Reduction in levels of 24S-hydroxycholesterol by statin treatment in patients with Alzheimer disease. Arch Neurol 60 (2003) 510-5.

[10] Johnson-Anuna LN, Eckert GP, Keller JH, Igbavboa U, Franke C, Fechner T, Schubert-Zsilavecz M, Karas M, Müller WE, and Wood WG. Chronic administration of statins alters multiple gene expression patterns in mouse cerebral cortex. $\mathrm{J}$ Pharmacol Exp Ther 312 (2005) 786-93.

[11] Nagy J. The NR2B subtype of NMDA receptor: a potential target for the treatment of alcohol dependence. Curr Drug Targets CNS Neurol Disord 3 (2004) 169-79.

[12] Du X, Elberger AJ, Matthews DB, and Hamre KM. Heterozygous deletion of NR1 subunit of the NMDA receptor alters ethanol-related behaviors and regional expression of NR2 subunits in the brain. Neurotoxicol Teratol 34 (2012) 177-86.

[13] Ward RJ, Lallemand F, and de Witte P. Biochemical and neurotransmitter changes implicated in alcohol-induced brain damage in chronic or 'binge drinking' alcohol abuse. Alcohol Alcohol 44 (2009) 128-35.

[14] McCool BA, Christian DT, Diaz MR, and Läck AK. Glutamate plasticity in the drunken amygdala: the making of an anxious synapse. Int Rev Neurobiol 91 (2010) 205-33.

[15] Rubio M, Villain H, Docagne F, Roussel BD, Ramos JA, Vivien D, Fernandez-Ruiz J, and Ali C. Pharmacological activation/inhibition of the cannabinoid system affects alcohol withdrawal-induced neuronal hypersensitivity to excitotoxic insults. PLoS One 6 (2011) e23690.

[16] Cole JC, Littleton JM, and Little HJ. Acamprosate, but not naltrexone, inhibits conditioned abstinence behaviour associated with repeated ethanol administration and exposure to a plus-maze. Psychopharmacol 147 (2000) 403-11.

[17] File SE, Andrews N, al-Farhan M, and Wu PY. The role of 5 -HT in the anxiogenic effects of acute ethanol withdrawal and in the long-lasting cognitive deficits. Alcohol 2 (1993) 495-9.

[18] Zhang Z, Morse AC, Koob GF, and Schulteis G. Dose and time-dependent expression of anxiety-like behavior in the elevated plus-maze during withdrawal from acute and repeated intermittent ethanol intoxication in rats. Alcohol Clin Exp Res 31 (2007) 1811-9.

[19] Uzbay T, Kayir H, Celik T, and Yüksel N. Acute and chronic tianeptine treatments attenuate ethanol withdrawal syndrome in rats. Prog Neuropsychopharmacol Biol Psychiatry 30 (2006) 478-85.

[20] Kliethermes CL. Anxiety-like behaviors following chronic ethanol exposure. Neurosci Biobehav Rev 28 (2005) 837-50.

[21] Pandey SC, Zhang D, Mittal N, and Nayyar D. Potential role of the gene transcription factor cyclic AMP-responsive element binding protein in ethanol withdrawal-related anxiety. $\mathrm{J}$ Pharmacol Exp Ther 288 (1999) 866-78.

[22] Pellow S, Chopin P, File SE, and Briley M. Validation of open: closed arm entries in the elevated plus-maze as a measure of anxiety in the rat. J Neurosci Methods 14 (1985) 149-67.

[23] Prut L, and Belzung C. The open field as a paradigm to measure the effects of drugs on anxiety-like behaviors: a review. Eur J Pharmacol 463 (2003) 3-33.

[24] Cruz AP, Frei F, and Graeff FG. Ethopharmacological analysis of rat behavior on the elevated plus-maze. Pharmacol Biochem Behav 49 (1994) 171-6.

[25] Rodgers RJ, and Cole JC. An ethological analysis of chlordiazepoxide and bretazenil (Ro16-6028) in the murine elevated plus-maze. Behav Pharmacol 4 (1993) 573- 80.

[26] Setem J, Pinheiro AP, Motta VA, Morato S, and Cruz AP. Ethopharmacological analysis of 5-HT ligands on the rat 
elevated plus-maze. Pharmacol Biochem Behav 62 (1999) 515-21.

[27] Kalueff AV, Wheaton M, and Murphy DL. What's wrong with my mouse model? Advances and strategies in animal modeling of anxiety and depression. Behav Brain Res 179 (2007) 1-18.

[28] Lister RG. Ethologically-based animal models of anxiety disorders. Pharmacol Ther 46 (1990) 321-40.

[29] Kalueff AV, and Tuohimaa P. Grooming analysis algorithm for neurobehavioural stress research. Brain Res Brain Res Protoc 13 (2004) 151-8.

[30] Crews FT, Morrow AL, Criswell H, and Breese G. Effects of ethanol on ion channels. Int Rev Neurobiol 39 (1996) 283-367.

[31] Guimaraes FS, Carobrez AP, De Aguiar JC, and Graeff FG. Anxiolytic effect in the elevated plus-maze of the NMDA receptor antagonist AP7 microinjected into the dorsal periaqueductal grey. Psychopharmacol 103 (1991) 91- 4.

[32] Gatch MB, and Lal H. Animal models of the anxiogenic effects of ethanol withdrawal. Drug Dev Res 54 (2001) 95-115.

[33] Yan J, Xu Y, Zhu C, Zhang L, Wu A, Yang Y, Xiong Z, Deng C, Huang XF, Yenari MA, Yang YG, Ying W, and Wang Q. Simvastatin prevents dopaminergic neurodegeneration in experimental Parkinsonian models: the association with anti-inflammatory responses. PLoS One 6 (2011) e20945.
[34] Läck AK, Diaz MR, Chappell A, DuBois DW, and McCool BA. Chronic ethanol and withdrawal differentially modulate pre- and postsynaptic function at glutamatergic synapses in rat basolateral amygdala. J Neurophysiol 98 (2007) 3185-96.

[35] Roberto M, Schweitzer P, Madamba SG, Stouffer DG, Parsons LH, and Siggins GR. Acute and chronic ethanol alter glutamatergic transmission in rat central amygdala: an in vitro and in vivo analysis. J Neurosci 24 (2004) 1594-1603.

[36] Melendez RI, Vuthiganon J, and Kalivas PW. Regulation of extracellular glutamate in the prefrontal cortex: focus on the cystine glutamate exchanger and group I metabotropic glutamate receptors. J Pharmacol Exp Ther 314 (2005) 139-47.

[37] Kalivas, P.W. The glutamate homeostasis hypothesis of addiction. Nat Rev Neurosci 10 (2009) 561-72.

[38] Blednov YA, and Harris RA. Metabotropic glutamate receptor 5 (mGluR5) regulation of ethanol sedation, dependence and consumption: relationship to acamprosate actions. Int J Neuropsychopharmacol 11 (2008) 775-93.

[39] Umhau JC, Momenan R, Schwandt ML, Singley E, Lifshitz M, Doty L, Adams LJ, Vengeliene V, Spanagel R, Zhang Y, Shen J, George DT, Hommer D, and Heilig M.. Effect of acamprosate on magnetic resonance spectroscopy measures of central glutamate in detoxified alcohol-dependent individuals: a randomized controlled experimental medicine study. Arch Gen Psychiatry 67 (2010) 1069-77.

[40] Littleton, J.M. Acamprosate in alcohol dependence: implications of a unique mechanism of action. J Addict Med 1 (2007) 115-25. 